\title{
The heart in limb girdle muscular dystrophy
} A J van der Kooi, W G de Voogt, P G Barth, H F M Busch, F G I Jennekens,
P J H Jongen, M de Visser
Department of

Neurology, Academic

Medical Centre,

Amsterdam, The

Netherlands

A J van der Kooi

P G Barth

$M$ de Visser

Department of Cardiology, St Lucas

Hospital, Amsterdam, The Netherlands

W G de Voogt

Department of

Neurology, Academic

Hospital Dijkzigt,

Rotterdam, The

Netherlands

H F M Busch

Department of Neurology, Academic Hospital Utrecht, The

Netherlands

F G I Jennekens

Department of Neurology, Academic Hospital Nijmegen, The Netherlands

$\mathrm{P} J \mathrm{H}$ Jongen

Correspondence to: Dr A J van der Kooi, Academical Medical Centre, Department of Neurology, PO Box 22700, $1100 \mathrm{DE}$ Amsterdam, The Netherlands.

Accepted for publication 5 September 1997

\begin{abstract}
Objective-To assess the frequency, nature, and severity of cardiac abnormalities in limb girdle muscular dystrophy, and its relation to age and weakness in various genotypes.

Design-In 26 autosomal dominant, 38 autosomal recessive, and 33 sporadic strictly defined patients with limb girdle muscular dystrophy, cardiac evaluation included history, physical examination, chest $x$ ray, electrocardiography, 24 hour ECG Holter monitoring, and echocardiography. In 35 of the 71 autosomal recessive and sporadic cases muscle biopsies were available for sarcoglycan analysis.

Main results-Dilated cardiomyopathy was present in one autosomal dominant case and in three advanced autosomal recessive or sporadic patients, of whom two were found to have $\alpha$ sarcoglycan deficiency. Two of these three patients and three other cases showed ECG abnormalities known to be characteristic of the dystrophinopathies. A strong association between the absence of $\alpha$ sarcoglycan and the presence of dilated cardiomyopathy was found $(p=0.04)$. In six autosomal dominant cases there were atrioventricular (AV) conduction disturbances, increasing in severity with age and in concomitant presence of muscle weakness. Pacemaker implantation was necessary in four.

Conclusions-10\% of these patients had clinically relevant cardiac abnormalities. In autosomal dominant limb girdle muscular dystrophy one subtype characterised by muscle weakness and AV conduction disturbances is recognised. In the course of autosomal recessivel sporadic limb girdle muscular dystrophy, dilated cardiomyopathy may develop, probably related to deficiency of dystrophin associated proteins.

(Heart 1998;79:73-77)
\end{abstract}

Keywords: limb girdle muscular dystrophy; cardiomyopathy; AV conduction block; sarcoglycan

Cardiac involvement in muscular dystrophies is a well known complication. In Duchenne muscular dystrophy, Becker muscular dystrophy, and carriers of the dystrophin gene, assembled under the term dystrophinopathies, dilated cardiomyopathy and specific ECG abnormalities are frequent findings. ${ }^{1-9}$ In yet another type, that is, Emery-Dreifuss muscular dystrophy, conduction defects are a hallmark of the disease. ${ }^{10}$ There are, on the other hand, also muscular dystrophies such as Bethlem myopathy in which cardiac involvement is not present. $^{2}$ The occasional patient with heart problems due to a dystrophic process has been described in limb girdle muscular dystrophy, a clinically and genetically heterogeneous group of disorders (table 1). ${ }^{26-28}$ However, these reports contained either anecdotal cases or small series of limb girdle muscular dystrophy patients.

The present study was part of an inventory of all known cases of limb girdle muscular dystrophy in The Netherlands, and comprises the largest group of carefully diagnosed limb patients so far. The objectives were to assess (1) the frequency, nature, and severity of cardiac abnormalities, and (2) the correlation between cardiac involvement and mode of inheritance, age, and severity of muscle weakness.

\section{Methods}

STUDY POPULATION

Ninety seven patients (59 females, 38 males) from 66 families with limb girdle muscular dystrophy were included in this cross sectional study. They participated in an explorative study of all known cases of limb girdle muscular dystrophy in the Netherlands and were subjected to a strict diagnostic procedure to exclude other possible causes of limb girdle syndrome, and to assessment of muscle strength. ${ }^{29}$ Dystrophin analysis of muscle tissue was performed in 42 patients from 56 families. The remaining 14 families were either multiplex or consanguineous families comprising only affected females (4), affected individuals of both sexes (2), or affected males in whom restriction fragment length polymorphisms had excluded $\mathrm{X}$ linked inheritance (2), and families with sporadic females (6). Where relevant, dystrophin gene screening and karyotyping was performed.

Autosomal recessive inheritance was present in 38 patients out of 23 families, autosomal dominant inheritance in 26 patients from 10 families, and 33 cases were sporadic. Age and disease duration are listed in table 2 .

CARDIAC EVALUATION

Cardiac involvement was assessed by several non-invasive types of investigation. Medical and family history was taken, and a physical examination performed. Full inspiration chest radiographs were obtained in the standing or sitting position. A standard 12-lead ECG was carried out at rest in the supine position. Evaluation included a classification according to the Minnesota code. ${ }^{30}$

Ambulatory ECG monitoring on a Reynolds two channel recorder for a 24 hour period of routine daily activities was performed in all 
Table 1 Classification of limb girdle muscular dystrophy

\begin{tabular}{|c|c|c|}
\hline Subtype & $\begin{array}{l}\text { Chromosomal } \\
\text { localisation }\end{array}$ & Gene product \\
\hline \multicolumn{3}{|l|}{ Autosomal dominant, LGMD1 } \\
\hline${\text { LGMD } 1 A^{1112}}^{112}$ & $5 q$ & Not identified \\
\hline $\mathrm{LGMD}_{1 \mathrm{~B}}{ }^{1314}$ & $1 \mathrm{q}$ & Not identified \\
\hline \multicolumn{3}{|l|}{ Autosomal recessive, LGMD2 } \\
\hline LGMD2A & $15 \mathrm{q}$ & Calpain $^{15-17}$ \\
\hline LGMD2B & $2 \mathrm{p}^{1819}$ & Not identified \\
\hline LGMD2C & $13 \mathrm{q}^{20}$ & $\gamma$ Sarcoglycan $^{21}$ \\
\hline LGMD2D & $17 \mathrm{q}$ & $\alpha$ Sarcoglycan $^{22}$ \\
\hline LGMD2E & $4 q^{1}$ & $\beta$ Sarcoglycan ${ }^{2324}$ \\
\hline LGMD2F & $5 q$ & $\delta$ Sarcoglycan ${ }^{25}$ \\
\hline
\end{tabular}

patients above the age of 10 years. A computer was used to analyse the magnetic tapes, and all tapes were read by one technician.

Cross sectional and colour flow Doppler echocardiographic investigations were performed in all patients using a Hewlett-Packard Sonos 500 and 2500 (Hewlett-Packard, Camas, Washington, USA). Echocardiographic evidence for dilated cardiomyopathy consisted of an enlarged end diastolic left ventricle (above the 95th centile, adjusted for body surface area) together with impaired systolic function. Body surface area was calculated in all patients in whom measurement of weight and length was possible. If correction by surface area was not possible, an end diastolic diameter $>60 \mathrm{~mm}$ was considered pathological. Systolic function was considered impaired if fractional shortening was less than $25 \%$ or if global hypokinesia on cross sectional echocardiographic examination was seen, or both. ${ }^{31}{ }^{32}$ Regional wall motion abnormalities were recorded.

IMMUNOHISTOCHEMICAL STUDIES

Forty two serial cryostat sections of available muscle specimens of autosomal recessive and sporadic cases were studied for dystrophin and

Table 2 Results of cardiological investigations

\begin{tabular}{|c|c|c|c|}
\hline & Autosomal recessive & Sporadic & Autosomal dominant \\
\hline No of patients (male, female) & $38(15,23)$ & $33(11,22)$ & $26(12,14)$ \\
\hline Median age (years) & 36 (8 to 66$)$ & 31 (3 to 65$)$ & 39 (30 to 69$)$ \\
\hline Median disease duration (years) & 20 (2 to 52$)$ & $18(1$ to 58$)$ & $22(0$ to 50$)$ \\
\hline \multicolumn{4}{|l|}{ History/physical examination } \\
\hline (total) & 8 & 8 & 8 \\
\hline Hypertension & 7 & 8 & 1 \\
\hline Aortic valve prosthesis & 1 & & \\
\hline Myocardial infarction & & & 1 \\
\hline Palpitations & & & 4 \\
\hline Syncopal attack/dizziness & & & 2 \\
\hline Chest $x$ ray abnormalities & & & 2 \\
\hline ECG abnormalities (total) & $14^{\star}$ & $16^{\star}$ & $12^{\star}$ \\
\hline Abnormal axis & 3 & 1 & 2 \\
\hline Right bundle branch block & & 2 & \\
\hline Left bundle branch block & & 1 & \\
\hline $\mathrm{AV}$ conduction disturbances & & & 6 \\
\hline Wolff-Parkinson-White & & 1 & \\
\hline Rhythm disturbancest & 1 & 1 & 7 \\
\hline $\mathrm{T}$ wave inversion & & 1 & \\
\hline Abnormal ST segments & 8 & 7 & 6 \\
\hline High precordial voltages & & 1 & \\
\hline RS ratio $>1$ in lead V1 & 2 & 2 & \\
\hline Narrow $Q$ wave in lateral leads & 1 & 2 & \\
\hline \multicolumn{4}{|l|}{ Echocardiographic abnormalities } \\
\hline (total) & 2 & 3 & $6^{\star}$ \\
\hline Aortic stenosis & & & 1 \\
\hline Dilated cardiomyopathy & 1 & 2 & 1 \\
\hline Hypertrophic left ventricle & & & 3 \\
\hline Abnormal septum & 1 & 1 & 2 \\
\hline
\end{tabular}

${ }^{\star}$ One patient can show more than one ECG or echocardiographic feature; fatrial fibrillation, extrasystoles, and atrial rhythm.

$\mathrm{AV}$, atrioventricular. spectrin; 35 of these were available for $\alpha$ sarcoglycan screening. ${ }^{33}$

STATISTICAL ANALYSIS

$\chi^{2}$ Tests were used to analyse the relation between severity of the cardiac disorder and age and severity of weakness, respectively. In autosomal recessive and sporadic cases the relation between the absence of $\alpha$ sarcoglycan and the presence of dilated cardiomyopathy was also analysed. The cut off value for the severity of weakness was the loss of independent walking, because we considered this an important indicator for the progression of the disease. Because our study was cross sectional, the statistical relations can only suggest an association.

\section{Results}

A complete cardiological work up was available in 91 out of 97 patients $(94 \%)$. In three, Holter ECG was incomplete, and in three other wheelchair bound patients echocardiography was not available because of pulmonary interposition. None of the patients had symptoms related to chronic cardiac failure. All abnormal results are listed in table 2 .

\section{AUTOSOMAL RECESSIVE PATIENTS}

An ambulatory 44 year old male, and a 23 year old wheelchair dependent female had an RS ratio $>1$ in lead V1 on ECG. In the former, muscle sarcoglycan was normal. The latter also showed a deep lateral $\mathrm{Q}$ wave and in addition she had borderline echocardiographic abnormalities consisting of a slightly abnormal contraction pattern of the left ventricle. Her muscle biopsy specimen was not available for sarcoglycan analysis. One wheelchair dependent woman aged 47 had dilated cardiomyopathy with a fractional shortening of $15 \%$. She was born from consanguineous parents, and her brother died at the age of 19 years because of cardiac failure due to dilated cardiomyopathy. Her muscle biopsy specimen was also not available for sarcoglycan analysis. An ambulatory 23 year old woman showed an abnormal contraction pattern of the interventricular septum. Muscle tissue was available from one of her siblings for sarcoglycan analysis, and showed a reduction of $\alpha$ sarcoglycan. In a 46 year old wheelchair dependent patient with $\alpha$ sarcoglycan deficiency, no cardiac abnormalities were found (see also table 3).

\section{SPORADIC PATIENTS}

An ambulatory 44 year old male with normal sarcoglycan and a 17 year old wheelchair dependent girl showed an RS ratio $>1$ in lead V1 on ECG. The latter, and a 27 year old female who had great difficulty walking, also had a narrow $Q$ in the lateral leads, and they both had dilated cardiomyopathy. Both these patients turned out to have $\alpha$ sarcoglycan deficiency, but normal dystrophin. Another female aged 20 was found to have an abnormally contracting interventricular septum; her muscle biopsy was not available for sarcoglycan analysis. Of three other wheelchair dependent patients with $\alpha$ sarcoglycan deficiency, one 
Table 3 Relation of sarcoglycan deficiency to dilated cardiomyopathy in autosomal recessive and sporadic patients

\begin{tabular}{lll}
\hline \multirow{2}{*}{ a Sarcoglycan } & \multicolumn{2}{l}{ Dilated cardiomyopathy } \\
\cline { 2 - 3 } & Present & Absent \\
\hline Absent & 2 & 5 \\
Normal & 0 & 28 \\
Unknown & 1 & 20 \\
\hline
\end{tabular}

woman aged 20 had Wolff-Parkinson-White syndrome, and the other two, aged 16 and 10, had no cardiac abnormalities.

\section{STATISTICAL ANALYSIS}

$\chi^{2}$ Tests showed a strong association between the absence of $\alpha$ sarcoglycan and the presence of dilated cardiomyopathy (table $3 ; \mathrm{p}=0.04$ ).

\section{AUTOSOMAL DOMINANT PATIENTS}

In six of 15 cases from two families with autosomal dominantly inherited limb girdle muscular dystrophy, atrioventricular conduction disturbances were seen (fig 1), in the concomitant presence of muscle weakness. Because none of the patients had lost the ability to walk independently, a relation with weakness could not be established. $\chi^{2}$ Testing showed a significant relation between the severity of atrioventricular conduction disturbances and age $(p<0.001)$. These patients have been described in detail elsewhere. ${ }^{13}$ Two had first degree, two second degree, and two total atrioventricular block. Two patients had a history of syncopal attacks and dizziness, requiring implantation of a pacemaker at the age of 62 and 40 years, respectively. During our study two other patients developed symptomatic atrioventricular block. (Paroxysmal) atrial fibrillation was found in four autosomal dominant patients. One was found to have dilated cardiomyopathy, with an end diastolic diameter of $70 \mathrm{~mm}$ and poor contraction of all walls. In addition, two other patients showed abnormal contractions of the interventricular septum. Atrioventricular block was not associated with echocardiographic abnormalities.

In three cases from other autosomal dominant families, left ventricular hypertrophy was encountered. These patients had hypothyroidism, hypertension, and aortic valve stenosis with a peak systolic gradient of $40 \mathrm{~mm} \mathrm{Hg}$, respectively.

\section{Discussion}

There are five recent small reports on cardiological involvement in limb girdle muscular dystrophy. In only three of these $\mathrm{e}^{34-36}$ strict diag-

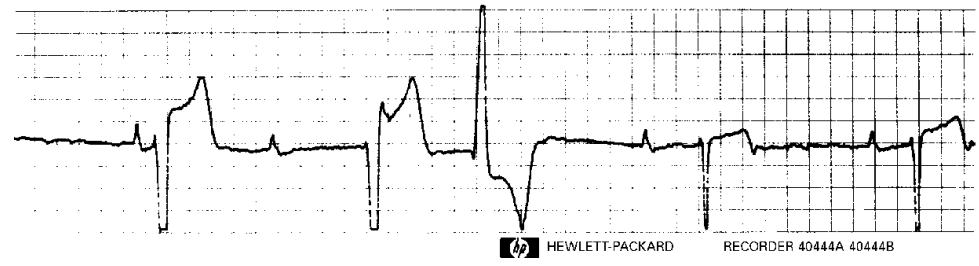

Figure 1 Rhythm strip of a member of the autosomal dominant families characterised by muscle weakness and atrioventricular conduction disturbances. After electroconversion from atrial fibrillation to sinus rhythm, total atrioventricular block with junctional escape rhythm, and a ventricular extrasystole were noted (paper speed $25 \mathrm{~mm} / \mathrm{s}$ ). nostic criteria for limb girdle muscular dystrophy have been used. In the study by Stübgen, ${ }^{34}$ which comprised 20 limb girdle muscular dystrophy patients, none of the patients had symptomatic heart disease. However, subclinical non-specific cardiac abnormalities were detected in $80 \%$. Whether these could be ascribed to a dystrophic process of the heart remains unclear. In the second study, ${ }^{35}$ describing 12 patients, two brothers with $\alpha$ sarcoglycan (previously called adhalin) deficiency and dilated cardiomyopathy have been mentioned. The third report describes a patient with dilated cardiomyopathy and $\alpha$ sarcoglycan deficiency who had previously been given a diagnosis of Becker muscular dystrophy. ${ }^{36}$ The remaining two reports described a patient with an impaired left ventricle function without associated dilatation, ${ }^{26}$ and three adult sisters with dilated cardiomyopathy. ${ }^{37}$ Recent detailed clinical descriptions of the different subtypes of limb girdle muscular dystrophy mention the absence of cardiac abnormalities in type $2 \mathrm{~B},{ }^{38}$ the very rare presence of abnormalities in type $2 \mathrm{~A},{ }^{39} 40$ and a high frequency of cardiac anomalies in type $2 \mathrm{C}$. ${ }^{41}$ These reports suggest that deficiency of one of the components of the dystrophin associated glycoprotein complex might cause dilated cardiomyopathy. The fact that the sarcoglycan complex is expressed in the heart ${ }^{42}{ }^{43}$ supports this view.

In this study, the largest so far conducted in which all patients have met strictly defined criteria for a diagnosis of limb girdle muscular dystrophy, various cardiac abnormalities were encountered. In our patient population dilated cardiomyopathy was present in three of 71 autosomal recessive or sporadic patients, comparable with the prevalence in dystrophinopathies. They were more advanced, but otherwise healthy, cases. Two were sporadic female patients, aged 17 and 27, respectively, both with $\alpha$ sarcoglycan deficiency. Although the numbers were small, $\chi^{2}$ testing nevertheless showed a strong association between the absence of $\alpha$ sarcoglycan and the presence of dilated cardiomyopathy. Direct mutation analysis of the genes encoding the four sarcoglycan subunits is needed to pinpoint the precise genotype, since absence of $\alpha$ sarcoglycan is always observed, no matter which of the sarcoglycans is lacking. ${ }^{44}$ These studies are currently in progress and may give more insight into the mechanism responsible for the involvement of cardiac muscle in some patients with limb girdle muscular dystrophy.

Interestingly, dystrophinopathy specific ECG abnormalities, including increased $\mathrm{R}$ waves in lead V1, an RS ratio > 1 in V1, and abnormal Q waves in the lateral leads, ${ }^{1-3}$ were found in the two sporadic females with dilated cardiomyopathy, and in three other patients (including two males). One of these three showed borderline echocardiographic abnormalities, consisting of a slightly abnormal contraction pattern of the left ventricle. Conceivably these ECG abnormalities may be considered an early stage in the development of dilated cardiomyopathy in limb girdle muscular dystrophy. 
In two families with autosomal dominantly inherited limb girdle muscular dystrophy, age related atrioventricular conduction disturbances were seen. Several patients developed symptomatic atrioventricular block. We strongly advocate 24 hour ECG recording, when ECG abnormalities suggesting atrioventricular conduction disturbances are present, in order to identify atrioventricular block at an early stage. Regular follow up examinations and implantation of a pacemaker if the patient becomes symptomatic are preventive measures. To a certain extent these families resemble EmeryDreifuss muscular dystrophy, but the absence of early contractures and rigid spine, the limb girdle distribution of weakness, and the mode of inheritance clearly distinguish these disorders. ${ }^{13}$

The occurrence of Wolff-Parkinson-White syndrome in one patient is probably of no significance because of its relatively high prevalence of $0.15 \%$ in the normal population. ${ }^{45}$ Hypertrophy of the left ventricle was found in three autosomal dominant patients in whom the underlying cause could be identified, that is, hypertension, hypothyroidism, and aortic valve stenosis.

Four patients (two autosomal dominant, one autosomal recessive, one sporadic) showed an abnormal contraction pattern of the interventricular septum on echocardiography. Whether this finding is indicative of involvement of the heart as part of the dystrophic process is as yet uncertain.

CONCLUSIONS

In summary, in $10 \%$ of our patients we found clinically relevant abnormalities, that is, atrioventricular conduction disturbances related to age in an autosomal dominant subtype and dilated cardiomyopathy in some advanced cases of the autosomal recessive/sporadic group. This refutes the previous notion that cardiological abnormalities in limb girdle muscular dystrophy are uncommon.

A J van der Kooi is the recipient of a grant from the Prinses Beatrix Fonds. We thank the patients for their cooperation. We acknowledge Dr H B Ginjaar for performing dystrophin and $\alpha$ sarcoglycan analysis on muscle biopsy specimens, the technicians at the Department of Cardiology of the St Lucas Hospital for technical assistance and their support to the patients, and Professor K J Lie for helpful comments on our manuscript.

1 Perloff JK, Roberts WC, De Leon AC, O'Doherty D. The distinctive electrocardiogram of Duchenne's progressive muscular dystrophy. Am $\mathcal{F}$ Med 1967;42:179-88.

2 De Visser M, De Voogt WG, La Rivière GV. The heart in Becker muscular dystrophy, facioscapulohumeral dystrophy, and Bethlem myopathy. Muscle Nerve 1992;15:591-6.

3 Shy, and Bethem myopathy. Muscle Nerve 1992;15:591-6. Steare SE, Dubowitz V, Benatar A. Subclinical cardiomy-
opathy in Becker muscular dystrophy [abstract]. Br Heart $\mathcal{f}$ 1992;68:304-8.

4 Wiegand V, Rahlf G, Kreuzer H. Kardiomyopathie bei Trägerinnen des Duchenne-Gens. Z Kardiol 1984;73:18891.

5 Kamakura K, Kawai M, Arahata K, Koizumi H, Watanabe $\mathrm{K}$, Sugita H. A manifesting carrier of Duchenne muscula dystrophy with severe myocardial symptoms. I Neurol 1990;237:483-5.

6 Rinaldi JP, Artigou JY, Thomas D, et al. L'atteinte myocardiaque chez deux femmes transmettrices de la maladie de Duchenne de Boulogne. Arch Mal Coeur 1991;84:401-4.

7 Shigihara-Yasuda $\mathrm{K}$, Tonoki $\mathrm{H}$, Goto Y, et al. A symptomatic female patient with Duchenne muscular dystrophy diagnosed by dystrophin staining: a case report. Eur 7 Pediatr 1992;151:66-8.

8 Watanabe K, Izumi T, Natsui M, et al. Dystrophin negative skeletal and myocardial muscle cells in a carrier of Duchenne's muscular dystrophy. Eur Heart f 1993;14:989Duchen

9 Mirabella M, Servidei S, Manfredi G, et al. Cardiomyopathy may be the only manifestation in female carriers of Duchenne muscular dystrophy. Neurology 1993;43:2342-5.
10 Yates JRW. Workshop report: European workshop on Yates JRW. Workshop report: European workshop on
Emery-Dreifuss muscular dystrophy. Neuromuscul Disord 1991:1:393-6.

11 Gilchrist JM, Pericak-Vance MA, Silverman L, Roses AD. Clinical and genetic investigations in autosomal dominant limb girdle muscular dystrophy. Neurology 1988;37:5-9.

12 Speer MC, Yamaoka LH, Gilchrist JM, et al. Confirmation of genetic heterogeneity in limb-girdle muscular dystrophy: linkage of an autosomal dominant form to chromosome 5q. Am f Hum Genet 1992;50:1211-17.

13 Van der Kooi AJ, Ledderhof TM, De Voogt WG, et al. A newly recognized autosomal dominant limb girdle muscuar dystrophy with cardiac involvement. Ann Neurol 1996;39:636-42.

14 Van der Kooi AJ, Van Meegen M, Ledderhof TM, McNally EM, De Visser M, Bolhuis PA. Genetic localization of a newly recognized autosomal dominant limb-girdle muscular dystrophy with cardiac involvement (LGMD1B) to chromosome 1q11-21. Am f Hum Genet 1997;60:891-5.

15 Beckmann JS, Richard I, Hillaire D, et al. A gene for Beckmann JS, Richard I, Hillaire D, et al. A gene for by linkage. C R Acad Sci 1991;312:141-8.

16 Richard I, Broux O, Allamand V, et al. Mutations in the proteolytic enzyme calpain 3 cause limb-girdle muscular dystrophy type 2A. Cell 1995;81:27-40.

17 Young K, Foroud T, Williams P, et al. Confirmation of linkage of limb-girdle muscular dystrophy, type 2, to chromosome 15. Genomics 1992;13:1370-1.

18 Bashir R, Strachan T, Keers S, et al. A gene for autosomal recessive limb-girdle muscular dystrophy maps to chromosome 2p. Hum Mol Genet 1994;3:455-7.

19 Gilchrist JM, Leshner RT. Autosomal dominant humeroperoneal myopathy. Arch Neurol 1986;43:734-5.

20 Ben Othmane K, Ben Hamida M, Pericak-Vance MA, et al. Linkage of Tunisian autosomal recessive Duchenne-like muscular dystrophy to the pericentromeric region of chromuscular dystrophy to the pericentromeric
mosome 13q. Nature Genet 1992;2:315-17.

21 Noguchi S, McNally EM, Ben Othmane K, et al. Mutations in the dystrophin-associated protein gamma-sarcoglycan in chromosome 13 muscular dystrophy. Science 1995;270: $819-22$.

22 Roberds SL, Leturcq F, Allamand V, et al. Missense mutations in the adhalin gene linked to autosomal recessive muscular dystrophy. Cell 1994;78:625-33.

23 Lim LE, Duclos F, Broux O, et al. Beta-sarcoglycan: characterization and role in limb-girdle muscular dystrophy linked to 4q12. Nature Genet 1995;11:257-65.

24 Bönnemann CG, Modi R, Noguchi S, et al. Betasarcoglycan (A3b) mutations cause autosomal recessive muscular dystrophy with loss of the sarcoglycan complex. Nature Genet 1995;11:266-73.

25 Passos-Bueno MR, Moreira ES, Vainzof M, Marie SK, Zatz M. Linkage analysis in autosomal recessive limb-girdle muscular dystrophy (AR limb girdle muscular dystrophy) maps a sixth form to 5q33-34 (LGMD2F) and indicates that there is at least one more subtype of AR limb girdle muscular dystrophy. Hum Mol Genet 1996;5:815-20.

26 Monségu J, Duboc D, Freychet L, et al. L'atteinte cardiaque au cours de certaines maladies musculaires. A propos de 216 observations. Arch Mal Coeur Vaiss 1993;86:1421-6.

27 Antônio JH, Diniz MC, Miranda D. Persistent atrial standstill with limb girdle muscular dystrophy. Cardiology 1978; 63:39-46.

28 Bensaid J. ECG differentiation of muscular dystrophy types. Am Heart F 1993;125:1820-1.

29 Van der Kooi AJ, Barth PG, Busch HFM, et al. The clinical spectrum of limb girdle muscular dystrophy. A survey in The Netherlands. Brain 1996;119:1471-80.

30 Blackburn H, Keys A, Simonson E, Rautaharju P, Punsar S. The electrocardiogram in population studies. A classification system. Circulation 1960;21:1160-75.

31 The task force. Report of the WHO/ISFC task force on the definition and classification of cardiomyopathies. $\mathrm{Br}$ Heart f 1980;44:672-3.

32 Feigenbaum $\mathrm{H}$. Echocardiographic measurements and normal values. In: Echocardiography. Philadelphia: Lea and Febiger, 1994:658-83.

33 Nguyen TM, Ellis JM, Ginjaar IB, et al. Monoclonal antibody evidence for structural similarities between the central rod regions of actinin and dystrophin. FEBS Lett 1990;262:237-40.

34 Stübgen JP. Limb girdle muscular dystrophy: a non-invasive cardiac evaluation. Cardiology 1993;83:324-30.

35 Piccolo E, Roberds SL, Jeanpierre $M$, et al. Primary adhalinopathy: a common cause of autosomal recessive muscular dystrophy of variable severity. Nature Genet 1995 ; 10:243-5.

36 Fadic R, Sunada Y, Waclawik AJ, et al. Deficiency of a dystrophin-associated glycoprotein (adhalin) in a patient with muscular dystrophy and cardiomyopathy. $N$ Engl $\mathcal{F}$ Med 1996;334:362-5.

37 Mascarenhas DAN, Spodick DH, Chad D, et al. Cardiomyopathy of limb-girdle muscular dystrophy. $\mathcal{f} \mathrm{Am}$ Coll Cardiol 1994;24:1328-33.

38 Mahjneh I, Passos-Bueno MR, Zatz M, et al. The phenotype of chromosome 2p-linked limb-girdle muscular dystrophy. Neuromusc Disord 1996;6:483-90.

39 Fardeau M, Hillaire D, Mignard C, Feingold N, Feingold J, Mignard D, et al. Juvenile limb-girdle muscular dystrophy. Clinical, histopathological and genetic data from a small community living in the Reunion Island. Brain 1996;119: 295-308.

40 Fardeau M, Eymard B, Mignard C, Tomé FMS, Richard I, Beckmann JS. Chromosome 15-linked limb-girdle muscu- 
lar dystrophy: clinical phenotypes in reunion island and French metropolitan communities. Neuromusc Disord 1991;6:447-53.

41 Ben Hamida M, Ben Hamida C, Zouari M, Belal S, Hentati F. Limb-girdle muscular dystrophy 2C: clinical aspects. Neuromusc Disord 1996;6:493-4.

42 Ozawa E, Yoshida M, Suzuki A, Mizunu Y, Hagiwara Y, Noguchi S. Dystrophin-associated proteins in muscular dystrophy. Hum Mol Genet 1995;4:1711-16.
43 Nigro V, Piluso G, Belsito A, et al. Identification of a novel sarcoglycan gene at $5 \mathrm{q} 33$ encoding a sarcolemmal $35 \mathrm{kDa}$ glycoprotein. Hum Mol Genet 1996;5:1179-86.

44 Sewry CA, Taylor J, Anderson LVB, et al. Abnormalities in alpha, beta, and gamma-sarcoglycan in patients with limbgirdle muscular dystrophy. Neuromusc Disord 1996;6:467-

Zipes DP. Cardiac arrhythmias. In: Kelly WN, ed. Textbook of internal medicine. New York: J B Lippincott, 1992. 